\title{
Preferential Activation of Microsomal Diacylglycerol/Protein Kinase C Signaling during Glucose Treatment (De Novo Phospholipid Synthesis) of Rat Adipocytes
}

\author{
Robert V. Farese, Mary L. Standaert, Thomas P. Arnold, Kouji Yamada, Kiran Musunuru, \\ Herman Hernandez, Harald Mischak, * and Denise R. Cooper \\ James A. Haley Veterans' Hospital, the Departments of Internal Medicine and Biochemistry and Molecular Biology, University of South \\ Florida, Tampa, Florida 33612; and *Institute for Clinical Molecular Biology and Tumor Genetics, Munich, Germany 81377
}

\begin{abstract}
Glucose has been reported to increase the de novo synthesis of diacylglycerol (DAG) and translocate and activate protein kinase $C$ (PKC) in rat adipocytes. Presently, we examined the major subcellular site of PKC translocation/activation in response to glucose-induced DAG. Glucose rapidly increased DAG content and PKC enzyme activity in microsomes, but not in plasma membranes or other membranes, during a 30-min treatment of rat adipocytes. This glucose-induced increase in microsomal DAG was attended by increases in immunoreactive PKC $\alpha, \beta$, and $\epsilon$. Glucose-induced activation of DAG / PKC signaling in microsomes was not associated with a change in the translocation of Glut -4 transporters from microsomes to the plasma membrane, a biological response that is known to be stimulated by agonists, e.g., phorbol esters, which increase DAG / PKC signaling in plasma membranes, as well as in microsomes. In conclusion, an increase in de novo phospholipid synthesis, as occurs during glucose treatment of rat adipocytes, primarily activates DAG / PKC signaling in microsomes; moreover, this signaling response and biological consequences thereof may differ from those of agonists that primarily stimulate DAG/PKC signaling in the plasma membrane. (J. Clin. Invest. 1994. 93:1894-1899.) Key words: glucose • phospholipids • diacylglycerol • protein kinase $\mathrm{C} \bullet$ adipocytes
\end{abstract}

\section{Introduction}

Glucose has been reported to provoke rapid increases in diacylglycerol $(\mathrm{DAG})^{1}(1,2)$ and concomitantly increase the enzymatic activity (1) and/or the translocation (2) of protein kinase $\mathrm{C}(\mathrm{PKC})$ in rat adipocytes. Studies with labeled glucose in rat adipocytes have demonstrated that increases in DAG result largely, if not exclusively, from the metabolism of glucose through the pathway of de novo phospholipid (i.e., phosphatidic acid [PA]) synthesis (2). These changes in DAG and PKC have suggested that glucose can stimulate DAG/PKC signaling in rat adipocytes, and similar observations have been made in a variety of other $(3,4)$, but not all (e.g., see reference 5$)$, tissues.

Address correspondence to Robert V. Farese, M.D., Research Service (VAR 151), J. A. Haley Veterans' Hospital, 13000 Bruce Downs Boulevard, Tampa, FL 33612.

Received for publication 21 May 1993 and in revised form 28 December 1993.

1. Abbreviations used in this paper: DAG, diacylglycerol; KRP, KrebsRinger phosphate buffer; PA, phosphatidic acid; PKC, protein kinase $\mathrm{C}$; TPA, tissue plasminogen activator.

The Journal of Clinical Investigation, Inc.

Volume 93, May 1994, 1894-1899
Glucose-induced aberrations in DAG/PKC signaling, moreover, have been postulated to play a role in the pathogenesis of diabetic complications $(3,4)$, and may also be involved in the pathogenesis of insulin resistance, either by persistent $\mathrm{PKC}$ activation and downregulation of insulin receptor tyrosine kinase activity (6) or after more chronic glucose treatment, by partial depletion of PKC- $\beta$, as shown in rat adipocytes (7).

Although glucose appears to increase DAG/PKC signaling through stimulation of de novo PA synthesis in some tissues, it seems most likely that this DAG/PKC signaling is considerably different from that resulting from agonist-stimulated hydrolysis of phospholipids through receptor-mediated activation of phospholipase $\mathrm{C}$ and/or D in the plasma membrane. Such a difference may be anticipated as de novo PA and consequent DAG synthesis would be expected to occur primarily in the endoplasmic reticulum (8) rather than in the plasma membrane. Presently, we evaluated this question in rat adipocytes, both with respect to the major subcellular site of glucose-stimulated DAG/PKC signaling and the PKC isoforms that are involved.

\section{Methods}

As described previously $(2,5,7)$, rat adipocytes were prepared by collagenase digestion of rat epididymal fat pads obtained from $200-\mathrm{g}$ male Holtzman rats fed standard laboratory chow ad lib. The cells were suspended in glucose-free Krebs-Ringer phosphate buffer (KRP) containing $1 \% \mathrm{BSA}$, equilibrated for $30 \mathrm{~min}$ at $37^{\circ} \mathrm{C}$, and then treated with 0 (controls), 5,10 , or $20 \mathrm{mM}$ glucose (or in a few experiments, insulin [Elanco] or tetradecanoyl phorbol-13-acetate [TPA] [Sigma Chemical Co., St. Louis, MO]) for 1-30 min as indicated in the text. (It should be noted that rat adipocytes are stable for at least $3 \mathrm{~h}$ in glucose-free medium, and there is little or no change in basal or insulin-stimulated glucose transport during this time period.) All treatments were added in a retrograde sequence, and the duration of incubation was kept constant, i.e., $60 \mathrm{~min}$, for all samples. In experiments in which ${ }^{32} \mathrm{P}$-labeling of immunoprecipitable MARCKS protein was evaluated, 20-30-ml adipocytes were batch incubated for $2 \mathrm{~h}$ in 2 vol glucose-free KRB containing $30 \mathrm{mM}$ Hepes, $1 \% \mathrm{BSA}$, and $10 \mu \mathrm{Ci}$ of ${ }^{32} \mathrm{PO}_{4}$ ( New England Nuclear, Boston, MA). After this initial labeling period, the adipocytes were aliquoted into plastic tubes and treated with or without $10 \mathrm{mM}$ glucose for 1-30 min (as above, the total incubation period was constant, i.e., in this case, $150 \mathrm{~min}$, for all samples). Reactions were terminated by adding chilled KRP or KRB.

Unless indicated otherwise, adipocytes were washed and homogenized (Potter-Elvehjem homogenizer) in cold $0.25 \mathrm{M}$ sucrose buffer containing $20 \mathrm{mM}$ Tris/ $\mathrm{HCl}$ (pH 7.5), $1.2 \mathrm{mM}$ EGTA, $1 \mathrm{mM}$ PMSF, $20 \mathrm{mM} \beta$-mercaptoethanol, and $20 \mu \mathrm{g} / \mathrm{ml}$ leupeptin (buffer I). Homogenates were centrifuged either, as described previously $(2,5,7)$, to obtain cytosol and crude, Triton X-100-solubilized, total membrane fractions, or, exactly as described by Weber et al. (9), to obtain highly purified plasma membranes and microsomes and combined nuclearmitochondrial membrane fractions. 
Immunoreactive PKC in subcellular fractions was determined by methods largely described previously $(2,5,7)$, except for the use of a chemiluminescent (ECL kit; Amersham Corp., Arlington Heights, IL) detection system in some experiments, particularly those involving purified microsomes and plasma membranes. In all experiments, equal amounts of cytosolic or membrane protein from each of the treatment groups were analyzed in parallel on the same immunoblot. All antiPKC polyclonal antisera were raised by immunization of rabbits with peptides that are contained within the variable regions $\left(V_{3}\right)$ of the catalytic domains of each PKC isoform. Antisera for PKC $\alpha, \gamma, \sigma, \epsilon$, and $\zeta$ were obtained from Gibco (Grand Island, NY) (see references 10 and 11). Antiserum for $P K C \beta$ has been used extensively in previous studies $(2,5,7,11)$ and was obtained from Dr. John Mehegan and Dr. Bryan Roth, who have characterized this antiserum (12). As described previously (11), the epitope-recognizing specificity of each of these antisera was verified by showing that immunoreactivities of both adipocyte samples and PKC rat brain standards were no longer apparent when assays were conducted in the presence of an excess of the immunogenic peptide, which specifically blocks those antibodies that recognize the targeted amino acid sequence. As also described previously (11), $(a)$ rat brain PKC $\alpha, \beta, \gamma, \sigma, \epsilon$, and $\zeta$ standards (and corresponding rat adipocyte PKCs) migrated on SDS-PAGE at apparent molecular masses of $80,80,80,80,90$, and $75 \mathrm{kD}$, respectively; $(b)$ using each antiserum, there was a linear relationship between observed immunoreactivity and the amount of PKC assayed, except at saturating or extremely low amounts of PKC; and $(c)$ each of the antisera that were used did not cross-react with PKC isoforms (within the groups $\alpha, \beta, \gamma, \sigma, \epsilon$, and $\zeta$ ), other than that that was targeted, as tested with recombinant PKCs that were obtained from baculovirus-insect cell and NIH/3T 3 cell expression systems. DAG was measured by the method of Preiss et al. (13).

As described previously (14), membrane PKC enzyme activity was measured in vitro by the method of Chakravarthy et al. (15) as follows. Total postnuclear (i.e., post-500 $\mathrm{g} \times 5 \mathrm{~min}$ ) or purified plasma membrane or microsomal membrane fractions were examined for their ability to phosphorylate a soluble, exogenous, specific, 85-kD PKC substrate. (This $85-\mathrm{kD}$ PKC substrate appears to be a MARCKS protein, as evidenced by its acidic nature and heat stability [15] and as we have reported [14] by [a] its immunoprecipitation and immunodetection by anti-MARCKS antiserum; [b] its phosphorylation by recombinant PKC $\alpha$; and [c] complete inhibition of its phosphorylation by $10-100$ $\mu \mathrm{M}$ [half-maximal, $\sim 5 \mu \mathrm{M}$ ] PKC pseudosubstrate [Calbiochem Corp., La Jolla, CA ].) The membrane fractions were washed twice, and $150 \mu \mathrm{g}$ of membrane protein was suspended in $250 \mu \mathrm{l}$ buffer containing $1 \mathrm{mM} \mathrm{NaHCO}_{3}, 50 \mathrm{mM}$ Tris/ $\mathrm{HCl}$ (pH 7.5), $5 \mathrm{mM} \mathrm{MgCl} 2,200 \mu \mathrm{M}$ $\mathrm{NaVO}_{4}, 200 \mu \mathrm{M} \mathrm{NaP} \mathrm{O}_{7}, 2 \mathrm{mM} \mathrm{NaF}, 200 \mu \mathrm{M}$ PMSF, and $2 \mu \mathrm{M}$ $\mathrm{CaCl}_{2}$, and then incubated for $10 \mathrm{~min}$ at $37^{\circ} \mathrm{C}$ with $20 \mu \mathrm{M}\left[\gamma-{ }^{32} \mathrm{P}\right] \mathrm{ATP}$ $(4,000 \mathrm{cpm} / \mathrm{pmol})$ and boiled cytosol ( $50 \mu \mathrm{g}$ protein) obtained from S49T-lymphoma cells that are rich in the soluble 85-kD PKC substrate (kindly supplied by Dr. Balu R. Chakravarthy). After incubation, icecold EGTA solution (final concentration, $1 \mathrm{mM}$ ) was added to stop the reaction, membranes were removed by centrifugation at $4^{\circ} \mathrm{C}$ for $1 \mathrm{~h}$ at $100,000 \mathrm{~g}$, soluble proteins were resolved by SDS-PAGE, and the ${ }^{32} \mathrm{P}$ labeled, 85-kD PKC substrate contained therein was quantified by autoradiography and scanning laser densitometry. As reported previously (14), ${ }^{32}$ P-labeling of this soluble $85-\mathrm{kD}$ PKC substrate (which was added in excess) was linear with respect to time and the concentration of either membrane protein or other sources of PKC, e.g., we used column-purified, recombinant PKC $\alpha$ obtained from a baculovirus-insect cell expression system; no labeling of the soluble 85-kD PKC substrate was observed in the absence of membranes or other PKC sources; and there was no release of soluble $85-\mathrm{kD}^{32} \mathrm{P}$-labeled protein from membranes incubated in the absence of added soluble substrate. Further, the ${ }^{32} \mathrm{P}$-labeling of the $85-\mathrm{kD}$ PKC substrate is markedly stimulated by recombinant PKC, but (see reference 15) not by calcicalmodulin or CAMP, and the acidic, heat-stable, $85-\mathrm{kD}$ substrate is itself not PKC. It should be noted that, in the assay, the membranes were assayed in their "native" state (see reference 15), rather than after detergent solubilization and addition of exogenous phospholipids/
DAG, as frequently used with PKC assays using less specific substrates such as histone IIIs. Thus, measured PKC activity is a reflection of both membrane PKC content and endogenous PKC activators, such as membrane DAG, phospholipids, and possibly other substances.

As described previously (14), ${ }^{32} \mathrm{P}$-labeling of MARCKS protein in intact rat adipocytes was determined by subjecting equal amounts of ${ }^{32} \mathrm{P}$-labeled cellular protein (200-250 $\mu \mathrm{g}$ ) to immunoprecipitation by incubation for $16 \mathrm{~h}$ at $4^{\circ} \mathrm{C}$, first, with an excess (1:20 dilution) of anti-MARCKS antiserum (kindly supplied by Drs. Ivar Walaas, Otto Walaas, and Paul Greengard) obtained from rabbits inoculated with rat brain MARCKS protein (see reference 16) and, second, for 4-8 $\mathrm{h}$ with sheep anti-rabbit IgG antiserum (Sigma Chemical Co.). Resultant immunoprecipitates were collected by centrifugation at $100,000 \mathrm{~g}$ for $30 \mathrm{~min}$, washed three times, resuspended in Laemmli buffer (17), boiled for $10 \mathrm{~min}$, subjected to one-dimensional SDS-PAGE, and analyzed by autoradiography and scanning laser densitometry. In adipocytes, immunoprecipitable MARCKS migrates at an apparent molecular mass of $85 \mathrm{kD}$ on SDS-PAGE (14).

Translocation of Glut-4 glucose transporters from low density microsomes to the plasma membrane was measured essentially as described $(9,18-20)$, using anti-Glut-4 antiserum obtained from EastAcres Biologicals (Southbridge, MA; see references 19 and 20).

\section{Results}

Alterations in membrane diacylglycerol content. $10 \mathrm{mM}$ glucose provoked rapid $50-70 \%$ increases in microsomal DAG, which persisted throughout the 30-min treatment period (Fig. 1 and Table I). In contrast, there were no significant increases in DAG contents of the plasma membrane or nuclear-mitochondrial fraction during the $30-\mathrm{min}$ period of $10 \mathrm{mM}$ glucose treatment (Fig. 1 and Table I).

Alterations in PKC enzyme activity (85- $k D$ substrate phosphorylation in vitro.) As an indicator of PKC activation, we examined the enzymatic activity of various preparations of adipocyte membranes wherein PKC activation presumably occurs. In total postnuclear membranes that were obtained from control or glucose-treated adipocytes, $10 \mathrm{mM}$ glucose provoked, over a 10 -min period, increases of $150 \pm 6 \%$ ( mean \pm SE; $n=3$ experiments; $P<0.025$, paired $t$ test), and these increases

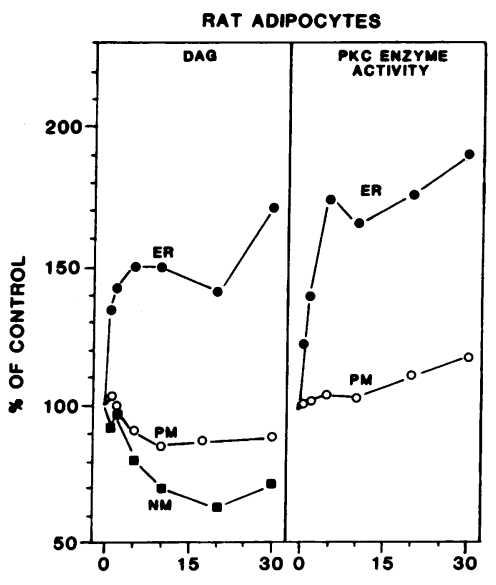

Figure 1. Time-dependent effects of glucose on diacylglycerol $(D A G)$ levels and PKC enzyme activity in membrane fractions of rat adipocytes. Adipocytes were equilibrated in glucose-free KRP medium containing $1 \%$ BSA and then treated for indicated times with $10 \mathrm{mM}$ glucose. Membrane fractions $(P M$, plasma membranes; $E R$, microsomes; $N M$, nuclei plus mitochondria) were purified and analyzed as described in Methods. Data are plotted as percent of the control. Changes in DAG membrane content and PKC enzyme activity (i.e., membranedependent 85-kD PKC substrate phosphorylation in vitro) are means of two closely agreeing experiments. Also see Table I for results from a larger number of experiments. 
Table I. Effects of Glucose Treatment on DAG Content and PKC Enzyme Activity in Plasma Membrane and Microsomal Fractions of Rat Adipocytes

\begin{tabular}{ccccc}
\hline \multicolumn{2}{c}{ DAG content* } & & \multicolumn{2}{c}{ PKC enzyme activity* } \\
\cline { 5 - 6 } $\begin{array}{c}\text { Plasma } \\
\text { membrane }\end{array}$ & $\begin{array}{c}\text { Microsomal } \\
\text { fraction }\end{array}$ & & $\begin{array}{c}\text { Plasma } \\
\text { membrane }\end{array}$ & $\begin{array}{c}\text { Microsomal } \\
\text { fraction }\end{array}$ \\
\hline$+2 \pm 9(7)$ & $+55 \pm 11(7)$ & & $+22 \pm 9(7)$ & $+107 \pm 20(7)$ \\
NS & $P<0.005$ & & NS & $P<0.001$ \\
& & & &
\end{tabular}

Adipocytes were equilibrated for $30 \mathrm{~min}$ in glucose-free KRP containing $1 \% \mathrm{BSA}$, and then incubated for another $10 \mathrm{~min}$ without (control) or with $10 \mathrm{mM}$ glucose. Shown here are glucose-induced changes (relative to controls) in DAG content and PKC enzyme activity (i.e., exogenous 85-kD PKC substrate phosphorylation in vitro) in plasma membrane and microsomal fractions. Mean values $\pm S E$ of $(n)$ experiments. $P$ was determined by paired $t$ test. ${ }^{*}$ Percent change due to $10 \mathrm{mM}$ glucose treatment versus control.

appeared to be maximal or near maximal within 5 min (Fig. 2). Upon further fractionation of membranes, increases in the PKC enzyme activity of microsomal, but not plasma membrane, fractions were observed during $10 \mathrm{mM}$ glucose treatment (Figs. 1 and 3, and Table I).

Translocation of PKC isoforms as determined by immunoblot analysis. We have reported previously that glucose stimulates the translocation of PKC enzyme activity and immunoreactive PKC $\beta$ from the cytosol to crude membrane fractions of rat adipocytes in a time- and dose-dependent manner $(2,5)$. This was presently confirmed for PKC $\beta$ in both dose-response (Fig. 4) and time course (Fig. 5) experiments, and effects of 10

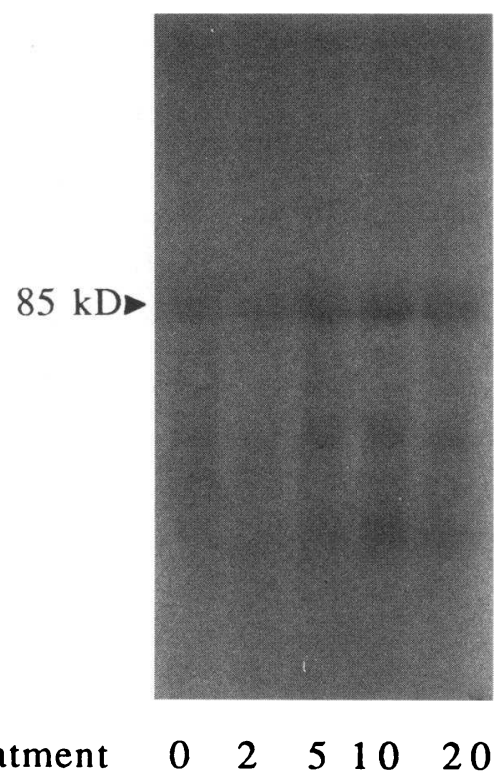

\section{Minutes of Treatment $\begin{array}{lllllll}0 & 2 & 5 & 1 & 0 & 2 & 0\end{array}$}

Figure 2. Effects of glucose on PKC enzyme activity of total postnuclear membranes of rat adipocytes. Rats were treated without (control, 0) or with $10 \mathrm{mM}$ glucose for the indicated times (2-20 min). Postnuclear membranes were then isolated and assayed for PKC activity, i.e., phosphorylation of soluble, exogenous $85-\mathrm{kD}$ substrate (MARCKS) in vitro, as described in Methods. Shown here is a representative autoradiogram.

\section{Plasma Membrane Microsomes}

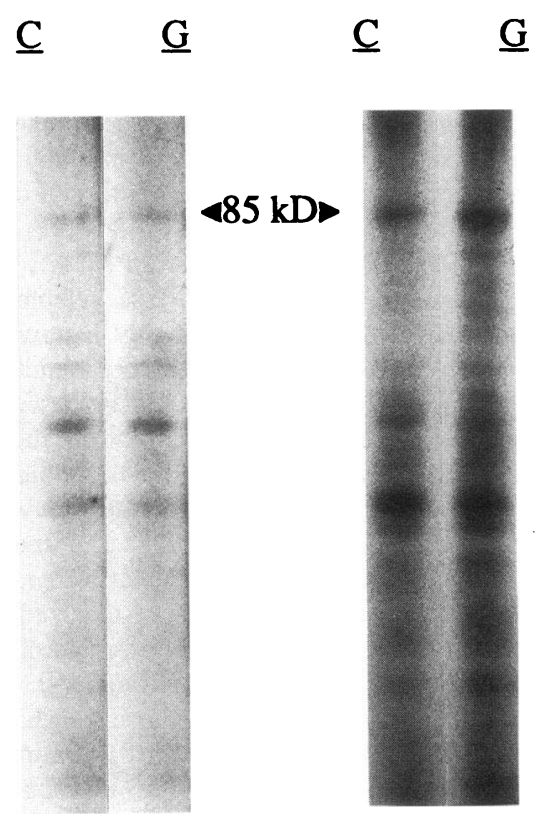

Figure 3. Effects of glucose on PKC enzyme activity of plasma membranes (left) and microsomes (right) of rat adipocytes. Adipocytes were treated for 10 min without (control, $C$ ) or with $(G) 10 \mathrm{mM}$ glucose. Membranes were then analyzed for PKC enzyme activity in vitro as described in Fig. 2. Shown here are representative autoradiograms. Also see Table I for results from multiple experiments.

$\mathrm{mM}$ glucose were also compared with those of the phorbol ester, viz., $500 \mathrm{nM}$ TPA (Fig. 5): as is apparent, peak increases in membrane PKC $\beta$ were frequently, although not always, observed at 5-10-min treatment with glucose or TPA, although cytosolic PKC $\beta$ continued to decrease over a 20-min period. As is also apparent, $500 \mathrm{nM}$ TPA was much more potent than 10 $\mathrm{mM}$ glucose in stimulating the translocation of PKC $\beta$. We also examined whether glucose provoked changes in the subcellular distribution of several other PKC isoforms that are found in rat adipocytes (11). Rat adipocytes were treated with 0 (control), 10 , or $20 \mathrm{mM}$ glucose for $10 \mathrm{~min}$, and the cytosol and crude membrane fractions were examined for changes in their contents of various immunoreactive PKC isoforms. As shown in Fig. 6, glucose-induced changes in PKC $\alpha$ or $\epsilon$ in these crude subcellular fractions were not readily apparent, although TPA was very effective in stimulating the translocation of these isoforms from cytosol to membrane. However, as shown below, we readily detected increases in microsomal PKC $\alpha$ and $\epsilon$ in response to glucose treatment, probably reflecting low basal

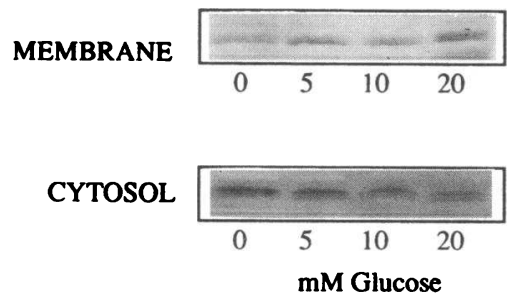

Figure 4. Dose-related effects of glucose on translocation of PKC $\beta$ from cytosol to crude total membranes of isolated rat adipocytes. Time of treatment was $10 \mathrm{~min}$. A representative immunoblot is shown here. 
CYTOSOL

Glucose
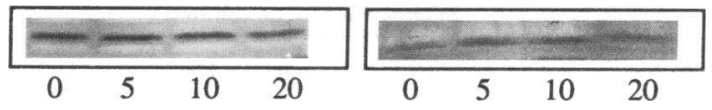

TPA
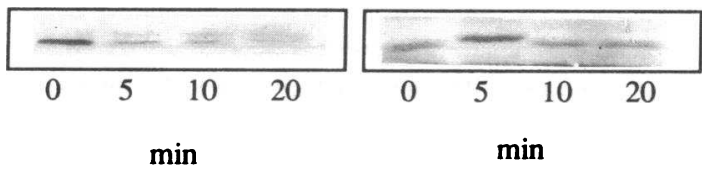

Figure 5. Time-dependent effects of glucose ( $10 \mathrm{mM})$ and TPA (500 $\mathrm{nM}$ ) on translocation of PKC $\beta$ from cytosol to crude total membranes of rat adipocytes. A representative immunoblot is shown here. $\alpha$
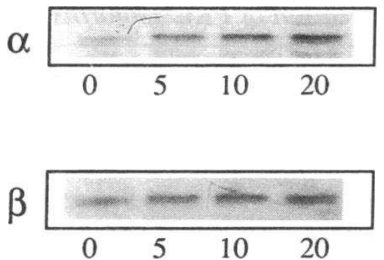

Glucose Treatment (minutes) $\varepsilon$
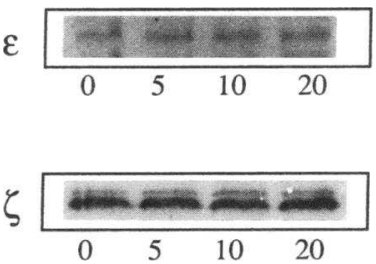

Glucose Treatment (minutes)

Figure 7. Effects of $10 \mathrm{mM}$ glucose on PKC isoforms $(\alpha, \beta, \epsilon$, and $\zeta)$ in microsomes of rat adipocytes. Adipocytes were incubated for 0 , 5,10 , or $20 \mathrm{~min}$ as indicated, and microsomal membranes were isolated and immunoblotted as described in Methods. Shown here are representative immunoblots. Also see Table II for results of multiple experiments.

brane. Whereas insulin or TPA treatment for $15 \mathrm{~min}$ provoked increases in Glut-4 translocation from low density microsomes ( $50 \%$ decreases) to the plasma membrane (two- to fourfold increases) (also reported previously, see references 20-23), 5 or $10 \mathrm{mM}$ glucose treatment for $15 \mathrm{~min}$ had little or no effect on this process (Table III). although it should be realized that PKC $\delta$ is largely membran associated even in the basal state (see reference 11), and PKC $\zeta$ lacks a DAG/TPA binding site.

We also examined changes in immunoreactive $\operatorname{PKC} \alpha, \beta, \epsilon$, and $\zeta$ in microsomal membranes in response to $10 \mathrm{mM}$ glucose treatment. As is apparent in Fig. 7 and Table II, there were consistent substantial increases in microsomal PKC $\alpha, \beta$, and $\epsilon$, but only a small change in PKC $\zeta$. In plasma membranes, PKC $\alpha$ increased modestly, but PKC $\beta$, $\epsilon$, and $\zeta$ were unchanged or diminished slightly (Table II).

$M A R C K S$ phosphorylation in intact rat adipocytes. To verify that PKC was truly activated by glucose treatment in intact adipocytes, we studied the phosphorylation of the specific PKC substrate, MARCKS. As shown in Fig. 8, rapid increases in endogenous MARCKS phosphorylation were observed in intact adipocytes in response to $10 \mathrm{mM}$ glucose treatment. The increases observed with $10 \mathrm{mM}$ glucose treatment were less than those reported previously (see reference 17) with TPA treatment (i.e., two- to fourfold).

Glut-4 translocation. In control adipocytes, as has been reported $(9,18-22)$, most $(>90 \%)$ immunoreactive Glut-4 was present in microsomes, with little $(<10 \%)$ in the plasma mem-

\section{CYTOSOL}

PKC- $\alpha$
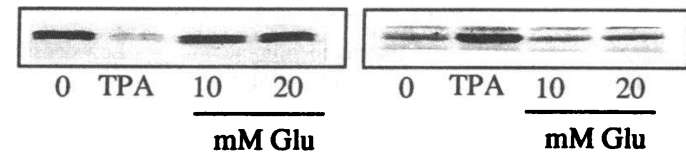

PKC- $\varepsilon$
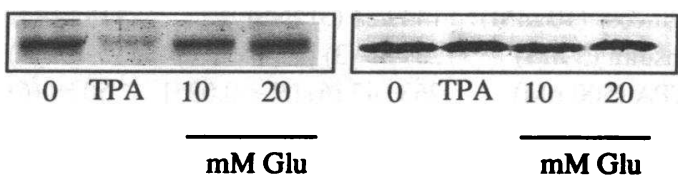

Figure 6. Effects of glucose and TPA on subcellular distribution of PKC $\alpha$ and $\epsilon$ in rat adipocytes. Adipocytes were treated for $10 \mathrm{~min}$ with 0 (controls), 10, or $20 \mathrm{mM}$ glucose, or $500 \mathrm{nM}$ TPA. Cytosol and crude total membrane fractions were obtained and immunoblotted as described in Methods.

\section{Discussion}

Presently, we found that glucose-induced increases in DAG content and PKC enzyme activity in the rat adipocyte were confined to or most evident in microsomal membranes, i.e., the endoplasmic reticulum, at least initially. As may be expected, these rapid glucose-induced changes in microsomal DAG content and PKC enzyme activity were accompanied by the translocation of DAG-sensitive isoforms, $\mathrm{PKC} \alpha, \beta$, and $\epsilon$, to microsomal membranes. In contrast to changes in microsomes, glucose did not provoke appreciable increases in plasma membrane-associated DAG, PKC enzyme activity, or immunoreactive $\mathrm{PKC} \beta, \epsilon$, or $\zeta$, although PKC $\alpha$ apparently increased modestly. The reason for the latter exception is presently uncertain, but the significance of this change in $\mathrm{PKC} \alpha$ is diminished by the fact that total PKC enzymatic activity did not increase significantly in the plasma membrane in response to glucose treatment. Nevertheless, further studies will be needed to determine whether more prolonged glucose treatment leads to more definitive changes in plasma membrane DAG/PKC, perhaps via intracellular lipid transfer.

It should be noted that both the relatively selective increases in microsomal DAG/PKC observed during glucose treatment and the extremely low levels of immunoreactive Glut-4 in control plasma membranes indicated that there was relatively little contamination of purified plasma membranes with microsomal membranes in the presently used cellular fractionation procedure. For these reasons, the glucose-induced increase in PKC $\alpha$ in the plasma membrane is unlikely to be due to contamination by microsomes, although this possibility cannot be entirely excluded. It may further be noted that, although it is unlikely that microsomal membranes were contaminated with significant amounts of plasma membranes, this potential problem would only have diminished the observed effects of glucose on microsomal DAG and PKC.

The relatively selective activation of microsomal DAG/ PKC signaling that occurs acutely in response to glucose treatment of rat adipocytes contrasts with rapid alterations induced 
Table II. Effects of Glucose on Translocation of PKC Isoforms to Microsomes and Plasma Membranes of Rat Adipocytes

\begin{tabular}{|c|c|c|c|c|c|c|c|}
\hline \multicolumn{4}{|c|}{ Plasma membrane PKC ( $\%$ control) } & \multicolumn{4}{|c|}{ Microsomal PKC (\% control) } \\
\hline PKC $\alpha$ & PKC $\beta$ & PKC $\epsilon$ & PKCS & PKC $\alpha$ & PKC $\beta$ & PKC $\epsilon$ & PKCS \\
\hline $\begin{array}{c}149 \pm 4(4) \\
(P<0.005)\end{array}$ & $\begin{array}{c}88 \pm 7(6) \\
\text { NS }\end{array}$ & $\begin{array}{c}88 \pm 18(4) \\
\text { NS }\end{array}$ & $\begin{array}{c}93 \pm 14(2) \\
\text { NS }\end{array}$ & $\begin{array}{l}183 \pm 15(4) \\
(P<0.025)\end{array}$ & $\begin{array}{c}202 \pm 33(5) \\
(P<0.05)\end{array}$ & $\begin{array}{l}163 \pm 18(5) \\
(P<0.025)\end{array}$ & $122 \pm 0(2)$ \\
\hline
\end{tabular}

Membranes were obtained after 5 or 10 min of treatment with $10 \mathrm{mM}$ glucose and subjected to Western analysis for PKC isoforms. Values are mean \pm SE of $(n)$ determinations. $P$ was determined by paired $t$ test.

by phorbol esters and insulin in these cells. As reported previously by Egan et al. (23) and confirmed in our laboratory using the same presently used subcellular fractionation procedures and in vitro PKC enzyme assay (14), both phorbol esters and insulin provoke rapid, sustained two- to threefold increases in PKC enzyme activity of both plasma membranes and microsomes of rat adipocytes. Furthermore, we have found that insulin rapidly increases the contents of DAG (14) and PKC $\alpha, \beta$, and $\epsilon$ (unpublished) in both plasma membranes and microsomes. Thus, the failure of glucose to provoke increases in DAG and PKC enzyme activity in adipocyte plasma membranes cannot be attributed to insensitive assay methods.

The translocation of PKC isoforms to specific intracellular membranes may be expected to result in specific alterations of PKC-dependent biological processes. It was therefore of interest to find that, although phorbol esters and insulin provoked increases in the translocation of Glut- 4 from microsomes to the plasma membrane, acute glucose treatment was inactive, or poorly active, in this regard. These findings indicate that $(a)$ glucose-induced translocation of $\mathrm{PKC} \alpha, \beta$, and $\epsilon$ to microsomal membranes is insufficient to stimulate the translocation of Glut-4; $(b)$ PKC-stimulated Glut-4 translocation must oc-

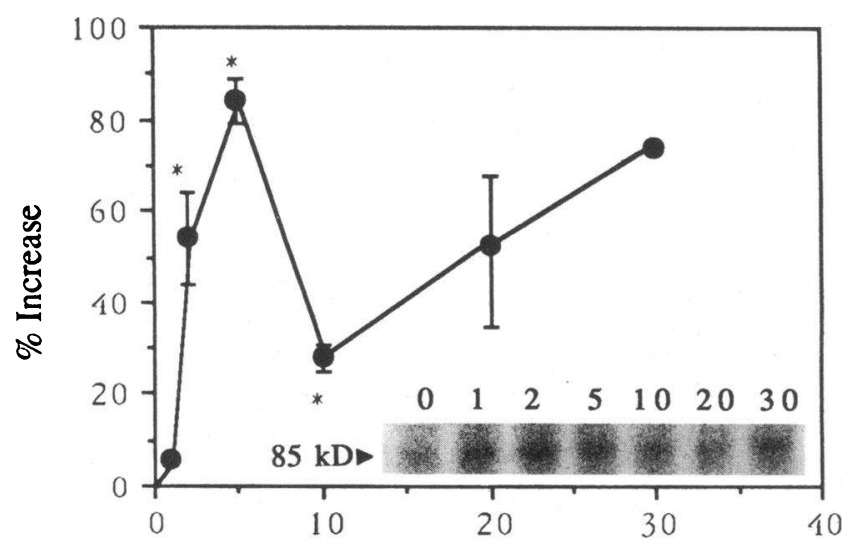

Minutes of Treatment

Figure 8. Effects of glucose on the phosphorylation of endogenous MARCKS in intact rat adipocytes. Adipocytes were incubated for a total of $150 \mathrm{~min}$ in the presence of ${ }^{32} \mathrm{P}$, and $10 \mathrm{mM}$ glucose was present during the last $30 \mathrm{~min}$ for the indicated times. Cell extracts were then obtained and subjected to immunoprecipitation with MARCKS antiserum, and precipitates were analyzed by SDS-PAGE and autoradiography, as described in Methods. Shown here are mean increases ( \pm SEM) over controls in three experiments. Shown in the inset is a representative autoradiogram of labeled, immunoprecipitable, $85-\mathrm{kD}$ MARCKS. cur by means of a metabolic process(es) that is distinct from the primarily microsomal PKC activation that is provoked by glucose-induced activation of de novo synthesis of PA and DAG; and $(c)$ at least initially, increases in peripheral glucose utilization that occur during hyperglycemia are more likely to result from a simple increase in "mass action" rather than an activation of the glucose transport process through a mechanism that involves Glut-4 translocation.

The fact that glucose preferentially stimulates DAG/PKC signaling in microsomes rather than in plasma membranes of rat adipocytes is important for several reasons. First, the DAG/ PKC signaling and its biological consequences that occur during glucose treatment of adipocytes are, at least in some respects, likely to be considerably different from those occurring during the action of agonists that activate adipocyte plasma membrane receptors. Second, agonists or nutrients that activate or provide substrate for de novo PA synthesis may be expected to activate DAG/PKC signaling in the endoplasmic reticulum. Third, the preferential activation of PKC in the endoplasmic reticulum could have particular relevance to the pathogenesis of PKC-dependent diabetic complications that are postulated to be triggered by elevation of serum glucose ( see references 3 and 4 ).

Finally, it should be realized that persistent PKC $\alpha$ activation in the plasma membrane by glucose could inhibit insulin receptor tyrosine kinase activity (see reference 6 ) and could thereby diminish insulin effects on various cellular processes. Also, persistent preferential activation of microsomal PKC $\alpha$, $\beta$, and $\epsilon$ may, at least in certain tissues such as the adipocyte, lead to proteolytic degradation and diminution of the cellular content of these PKC isoforms. Accordingly, since insulin stim-

Table III. Effects of Glucose, Insulin, and Phorbol Esters (TPA) on Translocation of Glut-4 in Rat Adipocytes

\begin{tabular}{lll}
\hline \multicolumn{1}{c}{ Treatment } & \multicolumn{1}{c}{$\begin{array}{c}\text { Plasma membrane } \\
\text { (\% of Control) }\end{array}$} & $\begin{array}{c}\text { Low density microsomes } \\
\text { (\% of Control) }\end{array}$ \\
\hline Glucose $(5 \mathrm{mM})$ & $134(1)$ & $116(1)$ \\
Glucose $(10 \mathrm{mM})$ & $144 \pm 24(3)[\mathrm{NS}]$ & $118 \pm 14(3)[\mathrm{NS}]$ \\
Insulin $(3 \mathrm{nM})$ & $289 \pm 5(3)[P<0.001]$ & $55 \pm 8(3)[P<0.025]$ \\
TPA (500 nM) & $263 \pm 43(6)[P<0.025]$ & $50 \pm 9(6)[P<0.005]$
\end{tabular}

Rat adipocytes were equilibrated for $30 \mathrm{~min}$ in glucose-free KRP containing $1 \% \mathrm{BSA}$, and then incubated for $15 \mathrm{~min}$ with or without (controls) indicated treatments. Plasma membrane and low density microsomes were then examined for immunoreactive Glut-4 levels. Mean values \pm SE of $(n)$ experiments. $P$ (in brackets) was determined by paired $t$ test. 
ulates the translocation of PKC $\alpha, \beta$, and $\epsilon$ to both plasma membranes and microsomes in rat adipocytes $(11,14$, and unpublished observations), it is possible that glucose-induced decreases in the availability of PKC (as occurring in rat adipocytes $[2,7])$ may lead to decreases in insulin-induced or other agonist-induced translocation of these PKC isoforms to the plasma membrane, and possibly to other nonmicrosomal membranes. Similarly, an increase in de novo synthesis of DAG, as occurs in denervated skeletal muscle (24), could limit insulin-induced PKC translocation to critical sites and thereby diminish insulin-stimulated glucose transport in skeletal muscle. Thus, the present findings may have relevance to the pathogenesis of both "glucotoxicity" and glucose-induced insulin resistance.

\section{Acknowledgments}

This work was supported by funds from the Research Service of the Department of Veterans' Affairs and National Institutes of Health grant DK-38079.

\section{References}

1. Draznin, B., J. W. Leitner, K. E. Sussman, and N. A. Sherman. 1988. Insulin and glucose modulate protein kinase $\mathrm{C}$ activity in rat adipocytes. Biochem. Biophys. Res. Commun. 156:570-575.

2. Ishizuka, T., J. Hoffman, D. R. Cooper, J. E. Watson, D. Pushkin, and R. V. Farese. 1989. Glucose-induced synthesis of diacylglycerol de novo is associated with translocation (activation) of protein kinase $C$ in rat adipocytes. FEBS (Fed. Eur. Biochem. Soc.) Lett. 249:234-238.

3. Lee, T. S., K. A. Saltsman, H. Ohashi, and G. L. King. 1989. Activation of protein kinase $\mathrm{C}$ by elevation of glucose concentration: proposal for a mechanism in the development of diabetic vascular complications. Proc. Natl. Acad. Sci. USA. 86:5141-5145.

4. Craven, P. A., C. M. Davidson, and F. R. DeRubertis. 1990. Increase in diacylglycerol mass in isolated glomeruli by glucose from de novo synthesis of glycerolipids. Diabetes. 39:667-674.

5. Hoffman, J. M., T. Ishizuka, and R. V. Farese. 1991. Interrelated effects of insulin and glucose on diacylglycerol-protein kinase-C signaling in rat adipocytes and solei muscle in vitro and in vivo in diabetic rats. Endocrinology. 128:29372948.

6. Muller, H. K., M. Kellerer, B. Ermel, A. Muhlhofer, B. Obermaier-Kusser, B. Vogt, and H. U. Hảring. 1991. Prevention by protein kinase $C$ inhibitors of glucose-induced insulin-receptor tyrosine kinase resistance in rat fat cells. Diabetes. 40:1440-1448.

7. Ishizuka, T., D. R. Cooper, T. Arnold, H. Hernandez, and R. V. Farese. 1991. Downregulation of protein kinase $C$ and insulin-stimulated 2-deoxyglucose uptake in rat adipocytes by phorbol esters, glucose, and insulin. Diabetes. 40:1274-1281.
8. Bell, R. M. 1980. Enzymes of glycerolipid synthesis in eukaryotes. Annu. Rev. Biochem. 49:459-487.

9. Weber, T. M., H. G. Joost, I. A. Simpson, and S. W. Cushman. 1988. Methods for assessment of glucose transport activity and the number of glucose transporters in isolated rat adipose cells and membrane fractions. C. R. Kahn and L. C. Harrison, editors. Alan R. Liss, Inc., New York. 171-187.

10. Henrich, C. J. 1991. Tools for the study of protein kinase $C$ and its isozymes. Focus (Idaho). 13:133-136.

11. Farese, R. V., M. L. Standaert, A. J. Francois, K. Ways, T. P. Arnold, H. Hernandez, and D. R. Cooper. 1992. Effects of insulin and phorbol esters on subcellular distribution of protein kinase $\mathrm{C}$ isoforms in rat adipocytes. Biochem. J. 288:319-323.

12. Roth, B. L., J. P. Mehegan, D. M. Jacobowitz, F. Robey, and M. J. Iadarola. 1989. Rat brain protein kinase C: purification, antibody production, and quantification in discrete regions of hippocampus. J. Neurochem. 52:215221.

13. Preiss, J., C. R. Loomis, W. R. Bishop, R. Stein, J. E. Niedel, and R. M. Bell. 1986. Quantitative measurement of $s n$-1, 2-diacylglycerols present in platelets, hepatocytes, and ras- and sis-transformed normal rat kidney cells. J. Biol. Chem. 261:8597-8600.

14. Arnold, T. P., M. L. Standaert, H. Hernandez, J. Watson, H. Mischak M. G. Kazanietz, D. R. Cooper, and R. V. Farese. 1993. Effects of insulin and phorbol esters on MARCKS phosphorylation (and other parameters of C-kinase activation ) in rat adipocytes, rat soleus muscle and $\mathrm{BC} 3 \mathrm{H}-1$ myocytes. Biochemistry. 295:155-164.

15. Chakravarthy, B. R., D. J. Franks, J. F. Whitfield, and J. P. Durkin. 1989. A novel method for measuring protein kinase $C$ activity in a native membrane-associated state. Biochem. Biophys. Res. Commun. 160:340-345.

16. Ouimet, C. C., J. K. Wang, S. I. Walaas, K. A. Albert, and P. Greengard. 1990. Localization of the MARCKS $(87 \mathrm{kDa})$ protein, a major specific substrate for protein kinase C, in rat brain. $J$. Neurosci. 10:1683-1698.

17. Laemmli, U. K. 1970. Cleavage of structural proteins during assembly of the head of bacteriophage $T_{4}$. Nature (Lond.) 227:680-685.

18. Simpson, I. A., D. R. Yver, P. J. Hissin, L. J. Wardzala, E. Karnieli, L. B. Salans, and S. W. Cushman. 1983. Insulin-stimulated translocation of glucose transporters in the isolated rat adipose cells: characterization of subcellular fractions. Biochim. Biophys. Acta. 763:393-407.

19. Corvera, S., S. Jaspers, and M. Pasceri. 1991. Acute inhibition of insulinstimulated glucose transport by the phosphatase inhibitor, okadaic acid. J. Biol. Chem. 266:9271-9275.

20. Farese, R. V., M. L. Standaert, B. Yu, H. Hernandez, and D. R. Cooper. 1993. 2-Hydroxypropyl- $\beta$-cyclodextrin enhances phorbol ester effects on glucose transport and/or protein kinase C- $\beta$ translocation to the plasma membrane in rat adipocytes and soleus muscles. J. Biol. Chem. 268:19949-19955.

21. Vogt, B., J. Mushack, E. Seffer, and H. U. Håring. 1991. The translocation of the glucose transporter sub-types GLUT1 and GLUT4 in isolated fat cells is differently regulated by phorbol esters. Biochem. J. 275:597-600.

22. Saltis, J., A. D. Habberfield, J. J. Egan, C. Londos, I. A. Simpson, and S. W. Cushman. 1991. Role of protein kinase C in the regulation of glucose transport in the rat adipose cell. Translocation of glucose transporters without stimulation of glucose transport activity. J. Biol. Chem. 266:261-267.

23. Egan, J. J., J. Saltis, S. A. Wek, I. A. Simpson, and C. Londos. 1990. Insulin, oxytocin, and vasopressin stimulate protein kinase $\mathrm{C}$ activity in adipocyte plasma membranes. Proc. Natl. Acad. Sci. USA. 87:1052-1056.

24. Chen, K. S., S. Heydrick, T. Kurowski, and N. B. Ruderman. 1991. Diacylglycerol-protein kinase $\mathrm{C}$ signaling in skeletal muscle: a possible link to insulin resistance. Trans. Assoc. Am. Physicians. 104:206-212. 